\title{
FESTSCHRIFT
}

\section{Applying the four principles}

\section{R Macklin}

J Med Ethics 2003;29:275-280

Gillon is correct that the four principles provide a sound and useful way of analysing moral dilemmas. As he observes, the approach using these principles does not provide a unique solution to dilemmas. This can be illustrated by alternatives to Gillon's own analysis of the four case scenarios. In the first scenario, a different set of factual assumptions could yield a different conclusion about what is required by the principle of beneficence. In the second scenario, although Gillon's conclusion is correct, what is open to question is his claim that what society regards as the child's best interest determines what really is in the child's best interest. The third scenario shows how it may be reasonable for the principle of beneficence to take precedence over autonomy in certain circumstances, yet like the first scenario, the ethical conclusion relies on a set of empirical assumptions and predictions of what is likely to occur. The fourth scenario illustrates how one can draw different conclusions based on the importance given to the precautionary principle.

Correspondence to:

Professor R Macklin,

Department of

Epidemiology and

Population Health, Albert

Einstein College of

Medicine, 1300 Morris

Park Ave, Bronx, New York

10463, USA

macklin@aecom.yu.edu

Accepted for publication 25 June 2003 s one who endorses the approach using the four principles, I maintain that they are always in need of interpretation and further analysis. Moreover, problems may lurk when applying them to specific cases. I shall comment on each of the four scenarios in turn.

\section{THE "STANDARD" JEHOVAH'S WITNESS CASE}

A traditional approach to the four principles might view the "standard" Jehovah's Witness case as a prominent example of a conflict of ethical principles. ${ }^{1}$ A competent adult patient is refusing a treatment that has the best chance of saving his life, according to well documented studies published in medical journals. Nevertheless, the respect for persons principle mandates that physicians should comply with the expressed wishes of a competent adult patient even if the predicted consequences are unfavourable or grave. Arguably, two ethical principles could support the opposite judgment: that the physician may-or must-seek to override the patient's refusal of a blood transfusion. The principle of nonmaleficence requires physicians to avoid harm, whenever possible, so withholding a proven, beneficial treatment is likely to have the consequence of producing harm. Although withholding a treatment is an omission rather than an action, it represents a deliberate decision taken by
A a physician and therefore, constitutes a course of action. The related principle of beneficence, which calls for maximising benefits and minimising harms, could also be used in support of the physician's duty to administer a blood transfusion in contravention of a patient's refusal.

If this is all that can be said about an analysis that relies on the four principles, this methodology could yield no clear resolution of the physician's dilemma. One reason no resolution is forthcoming is, as Gillon has pointed out, that "the four principles approach does not provide a method for choosing". ${ }^{2}$ The principles are not a set of ordered rules with instructions for making inferences and arriving at deductive conclusions. One of the common (and misguided) criticisms of the four principles is that they constitute a deductive system and therefore, presumably, a rigid method for arriving at solutions to complex ethical dilemmas. A quite different criticism of the method makes the opposite point, finding it deficient because it does not yield clear answers to troubling moral quandaries.

As Gillon notes, moral agents have to come to their own answers, using their preferred moral theories, and at the same time consider the set of common moral commitments provided by the four principles. ${ }^{2}$ Since I am in substantial agreement with Gillon on the soundness and utility of the four principles, I reject both criticisms: that the method is unacceptable because it is inflexible, and that the principles are useless because they fail to provide a unique solution to moral dilemmas.

Gillon's resolution of this dilemma brings the allegedly conflicting principles of respect for persons and beneficence into congruence. It is clear (at least prima facie) that respect for persons requires the physician to accede to the patient's refusal of a blood transfusion. What about the balance of benefits and harms? According to the patient's calculus of values, the harm resulting from receiving a transfusion (denial of eternal salvation) is greater than the harm caused by refusing the transfusion (the end of mortal life on earth). Arguably, this is a rational calculation for anyone who believes in the metaphysical scheme of the Jehovah's Witness faith. If one has to choose between eternal salvation and a few more years of mortal life in which one is merely "passing through," the choice of eternal salvation appears rational. From the perspective of the Jehovah's Witness, refusal of a blood transfusion has a favourable balance of benefits over harms.

Gillon argues, further, that the expense of a non-blood alternative treatment is not so great as to warrant overriding the patient's wishes based on a financial cost benefit assessment. ${ }^{1}$ Finally, rights based justice and legal justice are on the side of honouring the patient's wishes, so all three 
principles line up in favour of the conclusion that the ethical solution to the dilemma is to honour the Jehovah's Witness's refusal of blood transfusions.

While I find this solution compelling, based on the underlying moral presuppositions and empirical assumptions, we can imagine an alternative analysis-also using the four principles - that could arrive at a different conclusion. At least implicitly, Gillon's analysis gives great weight to the patient's stated wishes and, as a result, the respect for persons principle. Physicians who believe that their primary obligation is to save lives, when possible, will, however, almost always subordinate respect for persons to beneficence. More importantly, if the empirical facts are considerably different from what Gillon has hypothesised, it is at least plausible to think that accepting a patient's refusal of blood could cause more harm than good.

Consider the following scenario. The Jehovah's Witness patient is a married man with four children. His wife is not employed, as she is occupied rearing the children. The family lives in the US, not the UK, and they would have no health insurance for the family if the breadwinner dies. The wife has no occupational skills, and could therefore obtain only a low paying job if she were forced to go to work upon her husband's death. The husband has only a small life insurance policy that could support his family for a year or two after he dies. In addition, the closely knit Jehovah's Witness community becomes incensed when physicians override patients' refusal of blood. Elders of the church have urged Witnesses not to seek medical attention for conditions that might result in a recommendation of a blood transfusion. If that were to become a reality, there would be a likely increase in morbidity and mortality among Jehovah's Witnesses even in situations where they do not need blood transfusions. The net result would be a significant balance of harms over benefits, thereby contravening the principle of beneficence. On this scenario, the principles of respect for persons and beneficence are not congruent, but are in conflict.

Whether or not this scenario is plausible should not concern us. What is relevant to an analysis of this case is the scope of the principle of beneficence, that is, to whom the physician owes a moral obligation. In considering a patient's refusal of life saving treatment, is it appropriate to include harms that may come to others besides the patient-the patient's family or the Jehovah's Witness community? I am uncertain what Gillon would answer, since he notes that "the controversial issue of who falls within the scope of beneficence is answered unambiguously for at least one category of people": patients and clients of health care workers. ${ }^{2}$ Gillon does not discuss family members of patients or clients in his discussion of the scope of beneficence, although he poses the difficult question: "whom or what do we have a moral duty to help and how much should we help them?" In addition to the problem of scope, there is the classic methodological difficulty with utilitarian calculations: the difficulty of predicting which of several possible future scenarios will actually come about, and determining the likelihood of an array of potential good and bad consequences.

Let us consider one final possibility. There is anecdotal evidence that at least some Jehovah's Witnesses waver in their decisions when confronted with life threatening situations. They firmly refuse recommended blood transfusions, according to the teachings of their religion. They assert their refusals in the presence of family members and often, an elder of the church. But when offered the option of speaking alone with a physician, they relent and accept blood. Alternatively, when hospital authorities seek judicial intervention, a Jehovah's Witness may utter the standard objection, " . . against my will," yet in reality accept the transfusion. This possibility points to the difficulty in ascertaining whether a patient's stated wish is truly autonomous. Although it is generally true that people say what they mean and mean what they say, legitimate exceptions occur. The Jehovah's Witness who refuses blood in the presence of family members or an elder of the church may not be expressing an autonomous wish. In adhering to the respect for persons principle, physicians have an obligation to seek to determine whether their patients' refusals of recommended treatments are truly autonomous. If there is reason to suspect that a Jehovah's Witness patient's refusal of a blood transfusion is unduly influenced or lacking adequate understanding of the consequences, the physician should not accede immediately and unquestioningly to the patient's wish.

The foregoing considerations serve as a reminder that an ethical analysis using the four principles is complex. It requires an interpretation of the principles themselves in the context in which they are applied, as well as an accurate assessment of the factual circumstances of the situation. While I agree with Gillon's analysis of the "standard" Jehovah's Witness case, I have tried to show that a change in the background conditions could alter the conclusion that respect for persons and beneficence always line up in favour of accepting a competent adult patient's refusal of blood. Nevertheless, for the moral agent who is convinced that respect for persons always takes precedence over beneficence, any conflict between these two principles would still require the physician to adhere to the patient's refusal of blood. Moreover, because physicians owe stronger obligations to their patients than to other parties who may be affected (the patient's family or the community), it is ethically preferable to give priority to the patient's own assessment of the good and bad consequences of refusing of blood.

\section{THE "STANDARD" CHILD OF A JEHOVAH'S WITNESS CASE}

I am entirely in agreement with Gillon's conclusion that physicians are morally right to override the parents' refusal of a blood transfusion for their two year old child. For the most part, I agree with Gillon's moral reasoning. ${ }^{2}{ }^{3}$ There is one point, however, on which I disagree: that what the society regards as the child's best interest should be determinative of what really is in a child's best interest. In addition, it is worth considering a criticism of the "standard view" in the ethics literature, ${ }^{4}$ although I reject the approach taken by that critic.

Gillon's analysis of how to apply respect for persons in cases where parents are the decision makers for a child who clearly lacks the capacity to make medical decisions is clear and convincing. This lack of capacity means that the child is not (yet) an autonomous agent, and therefore someone else should be authorised to make decisions on behalf of the child. In most cases, the parents are the appropriate decision makers. The doctrine of "the best interest of the child" should, however, be the reigning theory in determining whether and when it is necessary or desirable to disqualify the presumptive decision makers in a particular situation. If the parents' decision is clearly against the best interest of the child, it is ethically permissible and sometimes legally required to disqualify them.

But what criteria should be used to determine what is in a child's best interest? Gillon's answer is as follows: respect for the decisions of the parents "is conditional upon social agreement that those decisions are in their child's best interests-or at least that they are not clearly against what society regards as being the child's interests" ( see Gillon ${ }^{3}, \mathrm{p}$ 33). To adopt the criterion of "social agreement" would plunge us into the morass of cultural and ethical relativism. Should it be the consensus of the Jehovah's Witness community in which the family lives that constitutes the relevant social agreement? Or must it be the social agreement of the majority of the country, say, the UK or the US, where the majority do not subscribe to the religious and metaphysical beliefs of Jehovah's Witnesses? (I refer to such non-scientific, unverifiable conditions as salvation or survival of the soul after death as "metaphysical beliefs".) This is a matter that Gillon should consider a 
question of scope. Why not take the Jehovah's Witness community as the relevant group in determining the existence of social agreement?

It is far from evident that what any society agrees upon is, therefore, morally right, even in that society and even if the majority of people in that society accept it. Slavery was accepted by a majority of people who lived in the American South before the civil war, but slavery is surely an unjust social arrangement when analysed according to the four principles. It may still be true that a majority of the people in some African countries accept the traditional practice of female genital mutilation, despite ample medical evidence of the physical harm, often lifelong, that results from that cultural practice. The penalty of amputation of the hands of common thieves in countries that adhere to strict Islamic law appears unacceptably harsh to other societies that consider the practice to be cruel and unusual punishment. These few examples show that mere social agreement cannot be sufficient for determining what is in anybody's best interest, even within the relevant society or cultural group.

In the case of the child of Jehovah's Witnesses, how can the child's best interest be determined? According to the beliefs of parents and others in the Jehovah's Witness community, the individual who receives a blood transfusion-whether a child or adult-will be denied eternal salvation. Physicians in the UK and US, along with judges who are called upon to adjudicate such cases, do not subscribe to this metaphysical belief. Instead, physicians and judges compare two alternative states of affairs for a child in need of a blood transfusion: a high probability of death or serious, irreversible morbidity, on the one hand, versus continued mortal life, on the other. Modern medical science provides an objective, reasonably accurate way of determining which of these consequences is more likely in any given circumstance. In cases of decision making for those who are incapable of deciding for themselves, these admittedly narrow, scientific grounds should be the basis for deciding what is in a person's best interest. As Gillon notes, there are borderline cases and hard cases, but the case of a child who could easily be restored to full health with a blood transfusion and would almost certainly die without the transfusion is neither borderline nor hard. ${ }^{1}$

A continued, healthy life and a premature death are not coequal values. Competent, adult patients should be permitted to decide for themselves whether other values override the usual wish they would normally have for a continued healthy life. Arguably (but still problematically), older adolescent children of adult Jehovah's Witnesses should be permitted to refuse blood if it can be ascertained that they are acting autonomously. But the two year old child has not yet developed a belief system or a value system on the basis of which to choose a hoped for eternal salvation over continued mortal life. There is no room for substituted judgments in the case of medical decision making for children. The doctrine of the best interest of the child is the only relevant basis on which others may decide on behalf of the child.

One philosopher rejects the best interest doctrine as a basis for the state's overriding parental refusal in the standard child of a Jehovah's Witness case. ${ }^{4}$ Mark Sheldon poses the question: "from whose perspective is 'harm' [to the child] being defined"? (see Sheldon ${ }^{4}, \mathrm{p}$ 254). In rejecting an argument that I advanced many years ago in discussing this situation, ${ }^{5}$ Sheldon contends that the death of a child need not be construed as harm to the child: "[Macklin] identifies 'harm' with 'death'. These are not necessarily the same" (see Sheldon ${ }^{4}$, p 254). Sheldon's critique maintains that whether harm is present depends on the perspective from which it is identified. "Also, what truly constitutes the 'welfare' of the child is a matter of perspective" (see Sheldon ${ }^{4}, \mathrm{p} 255$ ).

Sheldon's position rests on the assumption that there is no objective truth in "spiritual" matters, so there can be no expertise in determining what constitutes child welfare, benefit, best interest or harm: " . . . where the issue is ultimately spiritual and where obtaining eternal life is the objective, it is clear that the state can make no claim to any sort of knowledge" (see Sheldon ${ }^{4}, \mathrm{p} 256$ ). But if the state lacks knowledge of whether transfusion is ultimately harmful, Sheldon acknowledges, neither does anyone else know truly what is in the child's best interest. The parents' view regarding the child's best interest may also be mistaken. The proper role of the state is "to ensure that children ultimately become adults, able to decide, independently, what is in their own best interest" (see Sheldon ${ }^{4}$, p 256). Reluctantly, then, Sheldon comes down in favour of state intervention, but his argument is that it is justified on the basis of the incompetence of the child.

In the end, Sheldon's conclusion is the same as Gillon's and mine: it is justifiable for the state to override Jehovah's Witness parents' refusal of a blood transfusion for their child. Wherein lies the disagreement? We all agree that decisions for the non-autonomous patient must be made by someone else. We all acknowledge that normally it is a child's parents who should make the decision. Where we disagree is in whether there is an objective way of determining whether life or death is in a child's best interest. Since Sheldon views the possibility of eternal salvation as a spiritual matter, about which nothing can be known for certain, he cannot use the principle of beneficence to justify actions on behalf of non-autonomous children who are transfused in order to save their mortal lives.

My view, and I suspect it is Gillon's as well, is that the principle of beneficence provides the proper justification for saving the life of a child of Jehovah's Witness parents. An appeal to the unverifiability of metaphysical beliefs may be fine for those who entertain Cartesian doubts in the philosopher's armchair. But the practice of medicine must rely on empirical judgments about good and bad consequences here on earth.

\section{SELLING KIDNEYS FOR TRANSPLANTATION}

Gillon's analysis of this case demonstrates the flexibility in applying the four principles. ${ }^{1}$ Despite the centrality of respect for persons, and the (mistaken) view of some critics that adherents of the four principles always place the so called "American" principle of autonomy at the head of the list, Gillon demonstrates how considerations related to beneficence may justifiably override the autonomy of individuals who would seek to participate in a free exchange. ${ }^{6}$ Gillon argues persuasively that there is no good reason to doubt whether poor people who seek to sell their organs are, in general, able to make adequately autonomous decisions. But that does not constitute sufficient reason to endorse the practice. If the overall harms are likely to exceed the expected benefits-for the sellers, possibly for the society as a whole, and maybe even for the recipients of organs-it would be justifiable to ban the sale of organs from live donors. Here again, however, as in the standard case of the adult Jehovah's Witness, the conclusion relies on a set of empirical assumptions and predictions of what is likely to occur.

Gillon acknowledges that "harm benefit assessments are complex and contentious, and particularly difficult when they are predictive and prospective rather than retrospective ..." (see Gillon', p 117). How can we know, in the absence of empirical data, whether the organ sellers are in such poor health that their organs will be harmful rather than beneficial to donors? How can we assess the benefit to the sellers without information about how much they are paid, how they use the money, and whether the financial benefit is lasting rather than temporary? The case Gillon cites of the Turkish peasant who sold his kidney in order to purchase hospital care for his sick daughter is one of the best case scenarios. Are there worst case scenarios, as well? Ones in which a poor person sells a kidney in order to feed a drug habit or alcohol addiction? Or in which a poor person without medical insurance sells a kidney, 
develops an infection, and is unable to obtain necessary medical care to treat the infection and its aftermath?

Despite objections (raised by critics of utilitarianism) to the principle of beneficence as a basis for moral decision making, the principle itself is sound and respectable. The problem is that in the absence of a solid basis for predicting the probable good and bad consequences, people tend to draw a priori conclusions based on an antecedent acceptance or rejection of the social practice in question. Those who favour free market arrangements and the right of people to dispose of their property as they wish envisage happy financial outcomes for the poor people who sell their organs. As one defence contends: "we cannot improve matters by removing the best option poverty has left, and making the range smaller still". ${ }^{7}$ Another defence echoes this view, arguing that to deny the poor the opportunity to sell their organs leaves them worse off and thus exacerbates their poverty. ${ }^{8}$ A strong libertarian commitment underlies this position: "As a libertarian, I believe that people own themselves .... And as owners of themselves, individuals have the right to sell their organs, give them away, and even to allow themselves to be 'harvested' of their organs in a productive form of suicide, for whatever reason they choose." ${ }^{\prime \prime}$

Opponents of the sale of organs from live donors typically base their arguments on the supposition that the practice constitutes exploitation of the poor by the rich, or that it involves an unacceptable commodification of the human body. Both of these are thought to lead to a deterioration of the fabric of society and great overall harm. Some opponents reject the assumption that the human body should be treated as property-even the property of the living person whose body it is ${ }^{10}$ As one bioethicist wrote about the situation in India: "It is the poor who sell. Is this truly freedom, as the libertarian proclaims? Or is it a forced choice made in destitution and contrary to the seller's true human nature? I see such a market as the most demeaning form of human oppression, as unworthy of any valid human freedom". ${ }^{11}$

I concur with Gillon that the best analysis of this situation requires application of the principle of beneficence. But I also think that principle can be properly applied only when based on available empirical evidence rather than mere surmise about the likely consequences. One defender of organ selling by live donors cites the medical consequences to the donor as the only relevant factor in support of the safety of removing one kidney: “A 20 year follow up study showed no increase in mortality after kidney donation, and many patients undergo routine unilateral nephrectomy for kidney disease ${ }^{\prime \prime} .{ }^{12}$

Another defence contends that: "To justify total prohibition it would . . . be necessary to show that organ selling must always be against the interests of potential vendors, and it is most unlikely that this would be done" (see Gillon ${ }^{7}, \mathrm{p} 1950$ ). Surely that requirement is much too strong. It would be necessary only to show that on balance, organ selling produces more harm than good for all who stand to be affected. Although little evidence is available from well conducted studies, one recent investigation yielded the following results.

The study was designed to determine the economic and health effects of selling a kidney.

The subjects were 305 individuals in Chennai, India who had sold a kidney. Ninety six per cent of participants sold their kidneys to pay off debts. The average amount received was 1070 US dollars. Most of the money received was spent on debts, food, and clothing. Average family income declined by one third after nephrectomy $(\mathrm{P}<.001)$, and the number of participants living below the poverty line increased. Three fourths of participants were still in debt at the time of the survey. About $86 \%$ of participants reported a deterioration in their health status after nephrectomy. Seventy nine per cent would not recommend that others sell a kidney. ${ }^{13}$
The authors conclude that "Among paid donors in India, selling a kidney does not lead to a long term economic benefit and may be associated with a decline in health" ${ }^{13}$

Granted, these results are from only one small study in one country, yet they are revealing. As a basis for determining social policy, even one small study is undoubtedly worth more than a large number of idle speculations. Yet one problem remains. How can these economic, social, and health related harms be balanced against the benefits to the recipients who purchased the kidneys? This is the classic problem with the utilitarian calculus. Harms and benefits are neither quantifiable nor readily commensurable. Of course, if all of the organ recipients are benefited and not all the sellers are harmed, some utilitarians will conclude there is a net benefit. Moreover, if we compare the benefit to recipients of saving their lives with the harm to sellers of decrease in their health and financial status, the benefit harm balance still seems to tilt toward the recipients.

Even that does not settle the matter, as there are additional consequences to consider. One anthropological study found that the predominant reason for selling kidneys was the sellers' need to pay off high interest debts to local moneylenders. Many were back in debt within a few years. This could encourage organ brokers to intensify their search for sellers in areas that become known as "kidney zones". ${ }^{14}$ Another scholar, who headed a task force on transplantation and international traffic in organs, pointed out that as organs become available for purchase in some countries, other countries forgo promoting and facilitating organ donation. ${ }^{15}$ The net result is likely to be a sharp drop in donations from live, related family members, as well as a decrease in the supply of cadaveric organs.

Although these envisioned consequences still have to be supported by empirical evidence, they point to some uncertainty about the fundamental assumption that permitting the sale of kidneys from live donors will solve the problem of a shortage of organs. If that assumption remains in doubt, there is surely no good reason to accept the risks of physical, social, and financial harm to the already disadvantaged individuals who decide to sell their kidneys.

\section{GENETIC MANIPULATION TO PRODUCE GERMLINE TRANSMISSIBLE GENETIC ENHANCEMENT}

This scenario addresses two potentially controversial issues in bioethics: genetic enhancement and germline alterations. ${ }^{1}$ The first is easily dealt with. This is because the standard objections to genetic enhancement focus on attempts to improve various traits or abilities of healthy people, or to make individuals who are statistically or functionally within the normal range perform even better. When a proposed enhancement has a function analogous to a vaccine, boosting a person's immune system, however, it is intended to prevent disease. Since disease prevention is a central function of medicine and public health, enhanced protection against disease has not been questioned by opponents of other types of enhancement. Although arguments opposing genetic enhancement for other purposes are often flawed, they need not concern us here, as the scenario deals with a health related enhancement.

One argument that has been advanced against potential genetic enhancements may be relevant to the present case. That is the question of whether the proposed enhancement will be available and affordable to everyone in society. If not, then it is likely to violate the principle of justice, which calls for a fair distribution of benefits and burdens. In considering objections to germline intervention in his hypothetical case, Gillon says that "opponents of germline immunisation against AIDS could add that introducing is would also be distributively unjust unless it was introduced universally, which would be unlikely". ${ }^{16}$ 
Gillon is correct in noting that this is a general problem for all medications that are not introduced universally. We may question, however, whether there is something more unjust about providing enhancements to groups in society who are already more advantaged than those to whom the genetic enhancement will be unavailable. If an enhancement (medical or otherwise) is available only to the upper classes, it can further widen the already existing gap between the more advantaged and less advantaged members of society and thus exacerbate injustices. It is well established that members of poorer classes in every society have a worse health status than people in middle and upper classes, so the health gap would almost certainly widen if a genetic enhancement for immunisation were to be available only to the latter groups.

Let us assume, then, that the introduction of the gene conferring resistance to HIV will be made available to all. It would be rational for any country with a reasonably widespread public health system to make the preventive intervention widely available to all economic classes, assuming that it would be cheaper to do so than to pay for treatment of people who acquire HIV infection. Global justice would require that this genetic intervention be made available to resource poor countries, as well as to those countries that could readily afford the intervention, but that is a topic for a different analysis. If the genetic enhancement that confers resistance to HIV is available to all or almost all, then the principle of justice is satisfied.

The question of germline transmissibility poses harder questions. There have been two standard objections to germline interventions: first, that medical and scientific uncertainties accompany an intervention intended to continue for generations into the future, without the possibility of reversal if negative consequences occur down the line. This consideration focuses on the long range benefit harm ratio. The second objection is that future generations have not consented to this genetic alteration, so it is unethical for the present generation to introduce an irreversible genetic alteration that will affect them. This consideration allegedly invokes respect for autonomy-the informed consent of the future individuals who will be affected by the present intervention.

Let me begin with the second objection. It is a red herring and a misuse of the principle of autonomy, or respect for persons. It is trivially true that individuals or generations not yet in existence have not consented-indeed, cannot consent-to anything. They do not consent to being born in the first place. They do not consent to being born in poverty, or in a place where the environment is polluted. They do not consent to inheriting traits that their parents pass on to them and that they wish were somehow different (I have in mind things like hair colour, eye colour, short stature, and myopia, and not predictable severe mental retardation or fatal, degenerative diseases). The whole point of the germline intervention is to benefit the future generations by making them less susceptible to a terrible disease. The fact that they did not-and could not-consent to being protected in that way does not demonstrate that their autonomy was somehow violated. Their autonomy is not yet in existence, so there is nothing to be violated.

The only other consideration related to autonomy is the informed consent of the volunteers who serve as research subjects for clinical testing of the genetic intervention. Gillon addresses that concern, and rightly concludes that the technique should be accepted for clinical testing by willing and informed volunteers. ${ }^{16}$ Although the volunteers themselves will not benefit from the genetic enhancement, they expect that their offspring may benefit, as well as the children of their offspring and on down the line. The involvement in research of people who will not receive direct benefit is ethically acceptable, and is a feature of all phase I drug trials and baseline studies of various sorts. Arguably, the research subjects in this proposed clinical trial could receive some indi- rect benefit, if the intervention proves successful, as they may have the satisfaction of knowing that their children and their future progeny will have enhanced protection. Of course, anyone opposed to germline interventions or genetic enhancements need not volunteer for this research.

We are left, once again, with an ethical analysis that relies on a proper application of the principle of beneficence or its counterpart, non-maleficence. By hypothesis in this scenario, the technique had been shown to be safe in animal experiments. But what does "safe" mean when an intervention will continue to have effects in the very long range? In biomedical research, a product can be shown to be safe in animal experiments, and in phase I experiments in humans for the individuals who serve as subjects. Inserting the HIV resistant gene can be shown to be safe for the woman and her fetus in utero. But can it be shown-or assumed-to be safe for future generations?

It is difficult enough to demonstrate safety when negative effects of an entirely new product may not surface for many years or only in the next generation. A case in point is diethylstilboestrol (DES), a synthetic oestrogen that was prescribed to prevent miscarriages or premature delivery in pregnant women. Clinical trials had demonstrated that the product was safe in the women who took it; however, it was eventually implicated as a cause of vaginal cancer in daughters of many women who used the product during their pregnancy. The long term negative effects of a product introduced into the germline would be that much more devastating. Although somatic cell "gene therapy," as it is optimistically termed, has been in an experimental stage for more than twelve years, the only application that has shown moderate success was later found to have unacceptable side effects. The moderate success of gene therapy in children with severe combined immunodeficiency, a life threatening disorder, was followed by cases of leukaemia attributed to the intervention in several children.

This is where the "precautionary principle" enters in. As Gillon puts it, enthusiasts for the immunisation might overemphasise its possible benefits and give far too little weight to possible germline harms. ${ }^{16}$ While I support the use of thought experiments as useful tools in an ethical analysis, their persuasive power derives from the conditions stipulated by the proponent. Gillon asks us to accept the hypothetical premise that a safe, germline modification can be developed. We can accept that condition in a thought experiment, but as a matter of scientific reality it may remain an open question. The extreme caution that individual geneticists and scientific organisations have expressed regarding the unknowns, uncertainties, and potential dangers of germline interventions suggest that the precautionary principle may always be operative in this line of biomedical research. Instead of the "indefinite and exponentially increasing cascade of beneficence" hypothesised in Gillon's thought experiment, there may turn out to be an indefinite and exponentially increasing cascade of harms.

But none of these considerations constitute an argument against the approach using the four principles. Although Gillon's stipulation of the benefit harm ratio is hypothetical, it is none the less a plausible description of a possible state of affairs. Much less plausible are the negative consequences envisaged by opponents of germline interventions. To mention only a few of the more ludicrous suggestions: "IGM [inheritable genetic modification] might change attitudes toward the human person, the nature of human reproduction, and parent child relationships. IGM could exacerbate prejudice against people with disabilities". ${ }^{17}$ This litany of potential negative consequences is reminiscent of what was said about in vitro fertilisation before it became a reality in 1978, and similar also to current objections to human reproductive cloning. It is another illustration of opponents of a proposed action or policy inventing a fanciful array of worst case scenarios in seeking to demonstrate that the potential harms far outweigh the likely benefits. 
As one who endorses and uses the four principles approach in bioethics, I have no quarrel with Gillon's methodology or with the way he uses the principles in his analysis of cases. My comments on the four scenarios are intended simply to reiterate what Gillon acknowledges and we all know to be true: prospective application of the principle of beneficence is extraordinarily difficult because of our inability to make accurate predictions of good and bad consequences, as well as to determine which set of consequences has greater weight.

\section{REFERENCES}

1 Gillon R. Four scenarios. J Med Ethics 2003;29:267-8.

2 Gillon R. Medical ethics: four principles plus attention to scope. BM 1994:309:184-8.

3 Gillon R. Primum non nocere in paediatrics. In: Burgio G, Lantos J, eds. Primum non nocere today-a symposium on paediatric ethics. Amsterdam Elsevier, 1994. Exerpta medica international congress series 1073.

4 Sheldon M. Ethical issues in the forced transfusion of Jehovah's Witness children. J Emerg Med 1996;14:251-7.

5 Macklin R. Consent, coercion, and conflict of rights. Perspect Biol Med 1977;20:360-71.

6 Gillon R. Transplantation and ethics. In: Thomasma D, Kushner T, eds From birth to death-science and bioethics. Cambridge: Cambridge University Press, 1996.
7 Radcliffe-Richards J, Daar S, Guttman D, et al. The case for allowing kidney sales. Lancet 1998;351:1950-3

8 Kaserman DL, Barnett AH. The US organ procurement system: a prescription for reform. Washington, DC: American Enterprise System for Public Policy Research, 2002: 51

9 Kyriazi $\mathbf{H}$. The ethics of organ selling: a libertarian perspective. Available at www.pitt.edu and follow the links for the index (accessed 18 April 2003).

10 Joralemon D, Cox P. Body values: the case against compensating for transplant organs. Hastings Cent Rep 2003:33:27-33.

11 Post SG. Organ volunteers serve body politic. Insight 1995;11:20-2.

12 Friedlander MM. The right to sell or buy a kidney: are we failing our patients? Lancet 2002;359:971-3.

13 Goyal M, Mehta RL, Schneiderman LJ, et al. Economic and health consequences of selling a kidney in India. JAMA 2002;288: 1589-93. Abstract available at www.ncbi.nlm and follow the links for the index (accessed 18 April 2003).

14 Cohen L. Where it hurts: Indian material for an ethics of organ transplantation. Daedalus 1999;128:135-65.

15 Rothman DJ. Ethical and social consequences of selling a kidney. JAMA 2002;288: 1640-1.

16 Gillon R. Health care ethics, the four principles and the new genetics, In: Cooper DN, ed. The nature encyclopaedia of the human genome (vol 3). London: Macmillan, Nature Publishing Group, 2003: 180-4

17 Frankel MS, Chapman AR. Human inheritable genetic modification. Available at www.aaas.org and follow the links for the index laccessed 18 April 2003).

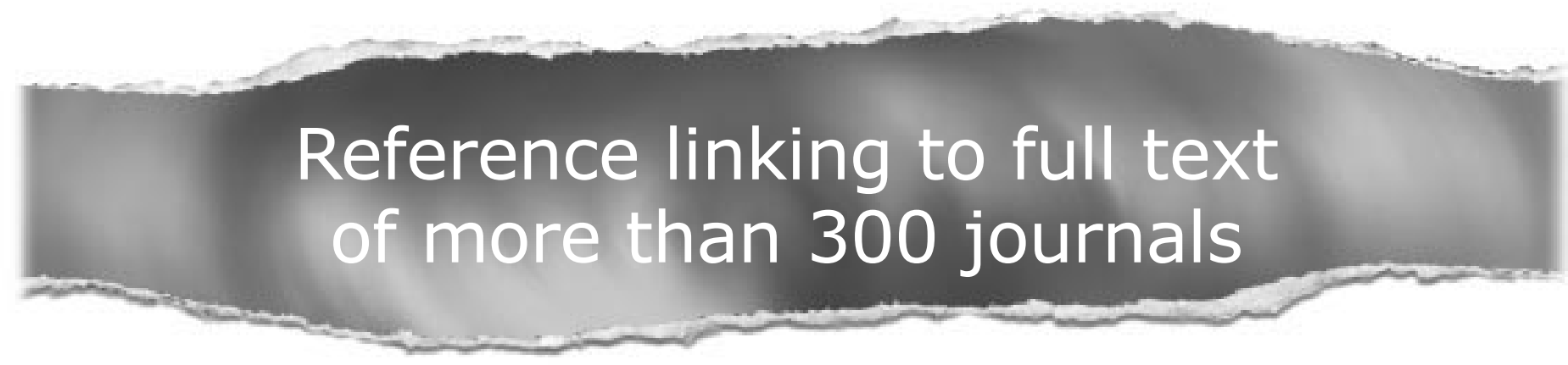

\section{Toll free links}

You can access the FULL TEXT of articles cited in the Journal of Medical Ethics online if the citation is to one of the more than 300 journals hosted by HighWire (http://highwire.stanford.edu) without a subscription to that journal. There are also direct links from references to the Medline abstract for other titles.

www.jmedethics.com 